\title{
3B.6 ENHANCING NEW YORK CITY'S RESILIENCE TO SEA LEVEL RISE AND INCREASED COASTAL FLOODING
}

\author{
Vivien Gornitz ${ }^{\star}$ Michael Oppenheimer, Robert Kopp, Radley Horton, Daniel A. Bader, Philip Orton, and \\ Cynthia Rosenzweig
}

\section{INTRODUCTION}

New York City, the largest city in the United States (population 8.5 million), is a leading center of global finance and commerce. The large population and major economic assets along the $837 \mathrm{~km}$ of New York City's extensive waterfront face exposure to sea level rise (SLR) and coastal flooding.

Notable historic coastal storm flood events include hurricanes in September, 1821, September,1893, and September, 1938, a nor'easter (extra-tropical cyclone) in December, 1992, and most recently, Hurricane Sandy on October, 29, 2012 (technically, a hybrid tropicalextratropical cyclone upon landfall in New Jersey). Sandy generated the highest water levels in at least 300 years (Talke et al. 2014; Orton et al. 2016), provoking 43 fatalities, hospital and nursing home evacuations, inundation of subways and tunnels. The storm flooded $17 \%$ of the city's land area, causing power outages for nearly two million people, as well as major transportation disruptions. Sandy was responsible for an estimated $\$ 19$ billion in damages (SIRR 2013). The extent and severity of the flooding were worsened by a rare combination of meteorological and tidal conditions, along with ongoing sea level rise.

Following Hurricane Sandy in 2012, New York City initiated a comprehensive future climate risk mitigation program, drawing upon the scientific expertise of the New York City Panel on Climate Change (NPCC), a special advisory group advisory group of academic and privatesector experts. The NPCC provides the city with scientific guidance on future climate risks, summarized in a series of reports published in 2010, 2013, and 2015. In response to the NPCC findings, New York City undertakes programs to strengthen coastal defenses, tailored to specific neighborhood needs. NPCC in collaboration with the city, continues to investigate vulnerability to extreme climate events, such as combined inland floods and coastal storms. New NPCC research in progress (Gornitz et al., 2019), outlined here, explores the consequences of an extreme highend, low probability sea level rise scenario, based on recent observations of increasing land ice mass losses, as well as advances in ice sheetocean-atmosphere modeling (Sweet et al, 2017; Kopp et al., 2017) and DeConto, R.M. and Pollard, D. (2016). These studies suggest that more elevated sea levels than previously assumed could become a physical possibility by 2100 , particularly under high-emissions futures.

Soaring sea levels would pose serious adverse consequences to people and built structures in low-elevation districts of New York City. We therefore present preliminary methods for a new high-impact sea level rise scenario, ARIM (Antarctic Rapid Ice Melt), which includes a possible Antarctic Ice Sheet destabilization. ARIM depicts a physically plausible upper-end, although low probability late $21^{\text {st }}$ century SLR scenario to be considered in long-term decisionmaking as an alternate upper-end sea level rise scenario. However, the NPCC (2015) projections still remain the scientific basis for New York City's coastal resiliency planning. We briefly summarize key processes that control sea level rise on global to local scales, observed trends, and review why New York City can expect higher a sea level rise than that of the projected global mean. We also briefly review the NPCC (2015) sea level rise projections for comparison with ARIM. Recent trends in land ice losses (glacier, ice sheets), described in NPCC (2019), reinforce the need to examine such an upper-end scenario. We then note steps undertaken by the city to improve and strengthen coastal resiliency.

\section{OBSERVED GLOBAL AND LOCAL SEA LEVEL RISE TRENDS}

\footnotetext{
* Corresponding author address: Vivien Gornitz, Center for Climate Systems Research/NASA Goddard Institute for Space Studies, New York, NY 10025, 212-678-5566; e-mail: vmg1@columbia.edu; Michael Oppenheimer, Princeton University; Robert Kopp, Rutgers University, New Brunswick, NJ; Radley Horton, Columbia University, New York, NY; Daniel A. Bader, Columbia University, New York, NY; Philip Orton, Stevens Institute of Technology, Hoboken, NJ; and Cynthia Rosenzweig, NASA Goddard Institute for Space Studies, New York, NY.
} 
Sea level rise represents one of the most momentous consequences of climate change, potentially affecting hundreds of millions of people living in coastal communities, worldwide. During most of the twentieth century, until the early 1990 s, global mean sea level rise averaged between 1 and $2 \mathrm{~mm} / \mathrm{yr}$ (Jevrejeva et al., 2017; 2014; Hay et al., 2015; Church et al., 2013). Between 1993 and 2017, the average global mean sea level rise, derived from satellite altimetry, is around $3 \mathrm{~mm} / \mathrm{yr}$, (Fig. 1; Watson et al., 2015; Dieng et al., 2017). Revised estimates, corrected for instrumental drift in earlier records, show a sea level rise acceleration due to increased losses of mass on glaciers and ice sheets within recent decades (Chen et al., 2017; Dieng et al, 2017; Nerem et al., 2018). Furthermore, post-late- $19^{\text {th }}$ century global-mean sea level rise has greatly exceeded the range of variability of the past two millennia (Kopp et al, 2016; Gehrels and Woodworth, 2013). These results suggest a two-stage acceleration of global mean sea level: the first from the late $19^{\text {th }}$-- early $20^{\text {th }}$ century to around 1990 , in part caused by natural climate cycles, and the second from the 1990 s to the present. Anthropogenic factors may now account for over 70 percent of the rise since 1970 (Slangen et al, 2016).

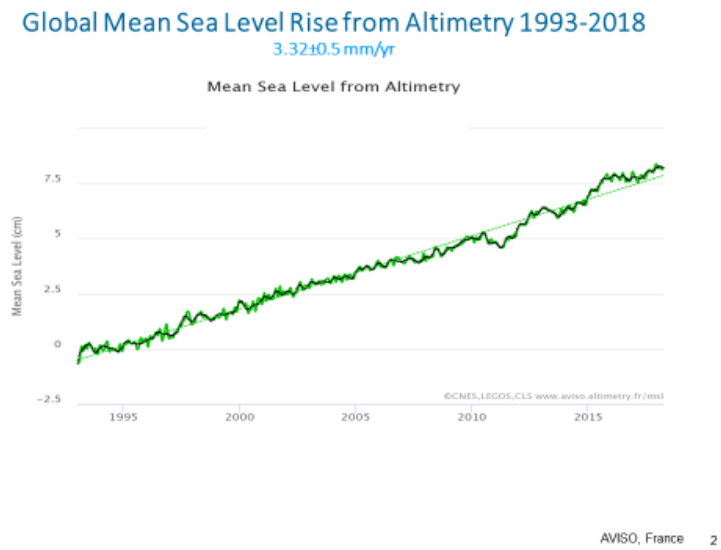

Figure 1. Global mean sea level rise during the satellite era, 1993-2018 (AVISO, France; posted March 26, 2018).

Multiple physical processes determine sea level rise on global to local scales. Among these are: (1) ocean density changes (temperature, salinity); (2) shifts in ocean circulation patterns; (3) ice mass losses from glaciers, ice caps, and ice sheets; (4) redistribution of ocean water caused by changes in the Earth's gravitation, rotation and deformation due to current ice mass losses (collectively termed "fingerprints"); (5) glacial isostatic adjustments (GIA), due the Earth's lithospheric response to removal of ice masses following the Last Ice Age; (6) other vertical land movements caused by ongoing tectonic activity, sediment compaction and loading, subsurface fluid extraction, and (7) changes in land water storage (e.g., in dams or from groundwater mining). Although thermal expansion and ice losses from mountain glaciers and small ice caps were the main contributors to observed mean global sea level rise, historically, shrinking ice sheets now play a growing role and will dominate in future higher-end global sea level rise scenarios (Slangen et al., 2017, 2016; Kopp et al, 2014; Church et al., 2013).

These processes interact in different ways spatially, such that at any given location the sum of the components for local sea level rise may differ significantly from the global mean. The New York City region is subject to higher than average sea level rise due to enhanced thermal expansion, GIA, and increasing ice losses from the ice sheets. Changes in ocean circulation may also become a growing factor in the future. The Atlantic Meridional Overturning Circulation (AMOC), for example, could slow down due to decreased North Atlantic salinity resulting from Greenland ice losses, increased precipitation, northern river freshwater inflow, and sea ice decline. A more sluggish North Atlantic circulation and weakened oceanic gyre would lead to a heat build-up and increased thermal expansion, which in turn would redistribute water mass shoreward especially in the mid-Atlantic region, including New York City (Krasting et al., 2016; Yin and Goddard, 2013; Yin et al., 2010; 2009).

Furthermore, in spite of the great distance separating Antarctica and New York City, effects of Antarctic ice losses are enhanced along the mid-Atlantic coast by the gravitational responses to this change. Ice mass attrition reduces the gravitational pull between ice sheet and ocean, such that water migrates farther from it. This, in addition to ongoing GIA-related land adjustment results in a higher than average local sea level rise. By contrast, gravitational effects from more proximal Greenland ice losses and northern hemisphere glaciers offset a part of the sea level rise from Greenland ice loss. The net effect of all these processes, however, drives New York City sea level rise above the global average (e,g., Carson et al., 2016; Kopp et al, 2014; Horton et al, 2015). This is illustrated by 
the twentieth century sea level trend in New York City of $2.8 \mathrm{~cm} /$ decade, which exceeded the global average (1.2-1.9 $\mathrm{cm} /$ decade), underscoring the heightened regional risk (Fig. 2).

Historic Sea Level Rise New York City, 1856-2017

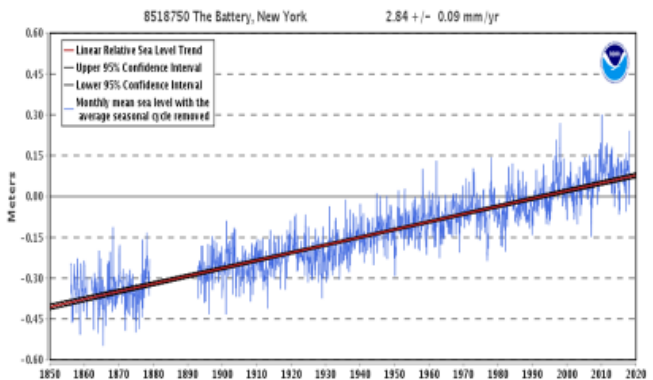

NOAA, 2018

Figure 2. Historic sea level rise 1856-2017, New York City, the Battery (NOAA, 2017).

\section{FUTURE NEW YORK CITY SEA LEVEL RISE}

\subsection{New York Panel on Climate Change SLR Projections}

In its 2015 report, the NPCC employed a multi-component methodology for projecting future sea level rise (Fig. 3, Horton et al., 2015). Components include oceanographic changes (thermal expansion, dynamic ocean height), ice mass losses and associated gravitational and glacial isostatic adjustments, also anthropogenic land water storage change, for an ensemble of 24 CMIP global climate models and two greenhouse gas emissions scenarios (RCP 4.5, RCP8.5 ), together with literature review and expert judgment for the ice sheet mass loss. Sea level rise, relative to the 2000-2004 base period, was determined for the $10^{\text {th }}, 25^{\text {th }}, 75^{\text {th }}$ and $90^{\text {th }}$ percentiles from a model-based distribution and estimated ranges from the literature.
Sea level Rise

Components-NPCC 2015

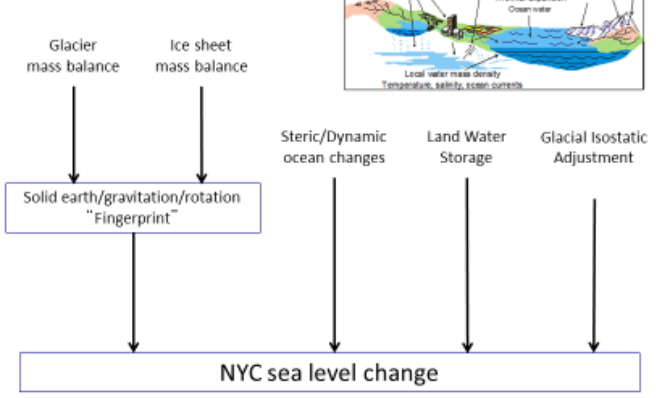

Figure 3. Schematic diagram of sea level components used in NPCC (2015).

Results indicate that sea level rises to $0.28-0.53 \mathrm{~m}$ at the Battery by the $2050 \mathrm{~s}$ and to $0.46-0.99 \mathrm{~m}$ by the $2080 \mathrm{~s}$ for the mid-range $\left(25^{\text {th }}\right.$ $75^{\text {th }}$ percentile), relative to a 2000-2004 baseline. High-end estimates ( $90^{\text {th }}$ percentile) climb to 0.76 $\mathrm{m}$ by the 2050s, $1.47 \mathrm{~m}$ by the $2080 \mathrm{~s}$, and to 1.91 $\mathrm{m}$ by 2100 (Table 1). It should be noted that the NPCC (2015) sea level rise projections represent the current science basis for New York City decision making and planning in accordance with the Climate Resiliency Design Guidelines.

\begin{tabular}{|c|c|c|c|}
\hline $\begin{array}{l}\text { Sea } \\
\text { level } \\
\text { rise } \\
\text { baselin } \\
\text { e } \\
(2000- \\
2004)\end{array}$ & $\begin{array}{l}\text { Low- } \\
\text { estimate } \\
\left(10^{\text {th }}\right. \\
\text { percentil } \\
\text { e) }\end{array}$ & $\begin{array}{l}\text { Middle } \\
\text { range } \\
\left(25^{\text {th }} \text { to }\right. \\
75^{\text {th }} \\
\text { percentil } \\
\text { e) }\end{array}$ & $\begin{array}{l}\text { High- } \\
\text { estimate } \\
\left(90^{\text {th }}\right. \\
\text { percentil } \\
\text { e) }\end{array}$ \\
\hline $2020 s$ & $+0.05 \mathrm{~m}$ & $\begin{array}{l}+0.10 \text { to } \\
0.20 \mathrm{~m}\end{array}$ & $+0.25 \mathrm{~m}$ \\
\hline $2050 s$ & $+0.20 \mathrm{~m}$ & $\begin{array}{l}+0.28 \text { to } \\
0.53 \mathrm{~m}\end{array}$ & $+0.76 \mathrm{~m}$ \\
\hline $2080 s$ & $+0.33 \mathrm{~m}$ & $\begin{array}{l}+0.46 \text { to } \\
0.99 \mathrm{~m}\end{array}$ & $+1.47 \mathrm{~m}$ \\
\hline 2100 & $+0.38 \mathrm{~m}$ & $\begin{array}{l}+0.56 \mathrm{t} \\
01.27 \mathrm{~m}\end{array}$ & $+1.91 \mathrm{~m}$ \\
\hline
\end{tabular}

* Based on 24 GCMs and two greenhouse gas emissions scenarios--4.5 and 8.5. Shown are the low- $\left(10^{\text {th }}\right.$ percentile), mid-range $\left(25^{\text {th }}\right.$ percentile to $75^{\text {th }}$ percentile), and high-end $\left(90^{\text {th }}\right.$ percentile) estimates.

RCP 6.0 appeared to be intermediate between RCP

\author{
4.5 and RCP 8.5
}

\footnotetext{
+ NPCC (2015) omitted RCP2.6 as unlikely, because of its overly optimistic mitigation assumptions, whereas
} 
Table 1. New York City sea level rise projections* for the 2020s, 2050s, and 2100, relative to 20002004, m (NPCC, 2015).

Until now, the NPCC (2015) has focused on sea level rise estimates that lie within the 10$90 \%$ probability range, but has not discussed sea level rise values with a higher (or lower) than $10 \%$ probability of occurrence by 2100 (in particular, very large sea level increases within the upper $10 \%$ tail of the probability distribution). Nevertheless, such high-end sea level rise outcomes may be of importance to many public or private sector decision-makers who need to examine the future of the City over longer timespans than risks playing out over shorter timescales of greater concern to the average homeowner - that of a standard home mortgage. Furthermore, the likelihood of sea level rise scenarios with a less than $10 \%$ change of occurring before 2100 may increase after 2100 , especially if greenhouse gas emissions are not eventually reduced (see further Section 3.2).

A new upper-end sea level rise scenario, briefly introduced in the next section, aims to meet the concerns of these stakeholders. Related ongoing research examines changes in storm characteristics, surge--sea level rise interactions, and mapping of neighborhoods at risk (NPCC, 2019).

Stakeholders interested in such high-end scenarios need to recall that our scientific understanding of processes affecting sea level rise, particularly involving the future role of ice sheets in such low probability, high impact situations, continues to evolve over time. Therefore, these should be regarded as offering a glimpse of a potential worst-case scenario, but premature to be used for actual planning purposes.

\subsection{Introducing the Antarctic Rapid Ice Melt (ARIM) Sea level Rise Scenario}

Antarctic ice losses recently exceed gains and furthermore, losses have generally been increasing since the 1990s (IMBIE TEAM, 2018). Furthermore, accumulating evidence points towards potential instability of the West Antarctic Ice Sheet (WAIS), which raises the prospect of higher future sea levels than

\footnotetext{
‡ Where the base of the ice sheet rests on bedrock below sea level.
}

previously foreseen (e.g., Sweet et al., 2017; Kopp et al., 2017, De Conto and Pollard, 2016). Melting of all marine-based WAIS ice ${ }^{\ddagger}$ would elevate global-mean sea level by up to about $3 \mathrm{~m}$ (Bamber et al., 2009). Much of WAIS is grounded (i.e., rests on land) below sea level, on reverse slopes. According to the Marine Ice Sheet Instability (MISI) hypothesis, an ice stream or glacier grounded on a reverse slope is inherently unstable, because as it reaches the grounding line, it will accelerate, stretch, thin, and discharge more ice, until the bed slope levels out (e.g., Davies, 2014). The process is enhanced by Warm Circumpolar Deep Water, a few degrees warmer than cold, near-surface water, which flows into a cavity beneath the ice shelf, where it melts the base of the glacier at the grounding line. This sets up a positive feedback that ultimately causes the ice shelf to thin, weaken, and break apart. The glacier then surges forward.

Grounding lines of a number of WAIS glaciers have receded within recent decades and their attached floating ice shelves have thinned. While the actuality of an ongoing MISI process remains uncertain (Joughin et al., 2014; Rignot et al., 2014), once initiated, projected $21^{\text {st }}$ century warming could potentially trigger catastrophic collapse starting late this century, and play out over several centuries or longer. Parts of East Antarctica are also potentially vulnerable to ocean warming (NPCC, 2018; Gornitz, 2018).

DeConto and Pollard (2016) presented an ice sheet/ice shelf model which includes hydrofracturing and ice-cliff collapse instabilities $(\mathrm{MICl})$, as well as MISI. These processes could accelerate ice mass losses and raise sea level, as explained further below.

In hydrofracturing, small cracks that form beneath meltwater pools on the ice shelf in summer propagate downward under water pressure. The cracks expand upon freezing in winter and deepen until ice eventually splits off. Additional stresses on thick ice cliffs and unbuttressed (unsupported) ice shelves induce grounding line fractures. Whereas intact ice shelves slow the advance of ice steams at the grounding line, heavily fractured ice shelves become more vulnerable to rapid disintegration. This allows glaciers and ice streams to surge across the grounding line and discharge more ice.

DeConto and Pollard (2016) suggest that continued high greenhouse gas emission rates 
could initiate ice shelf break-up via these mechanisms, starting after mid-century and add up to $1.6 \mathrm{~m}$ to sea level rise for Antarctica alone by 2100 . Collapse of the West Antarctic lce Sheet (WAIS) and some parts of the East Antarctica Ice Sheet could occur within a few hundred years at these high rates, potentially leading to over $15 \mathrm{~m}$ to global mean-sea level rise by 2500 . Even higher rates could be theoretically feasible, since this model caps the maximum ice-cliff retreat rate, which is as yet unknown.

Although DeConto and Pollard (2016) introduce newly-modeled ice sheet processes which could lead to future higher Antarctic ice mass losses, especially for higher greenhouse gas emissions scenarios, their paper represents a single study that remains to be confirmed by additional observations or modeling. Differences among several recent studies underscore deep uncertainties surrounding high-end sea-level rise projections. However, in spite of these differences, the potentially devastating consequences of such high-end eventualities emphasize the importance of exploring extreme outcomes, even although great uncertainty remains as to their probability.

In light of these considerations, a new low probability, yet high impact SLR scenario is developed for New York City. The ARIM (Antarctic Rapid Ice Melt) scenario incorporates several of the aforementioned ice sheet instabilities. The new SLR projections are subsequently combined with coastal flood return period curves to examine the 100-year storm flood levels and tidal (monthly) flooding effects (Section 4).

As described in NPCC (2019), the ARIM scenario screens a set of probabilistic projections from Kopp et al. (2017) to select a subset lying within $250 \pm 15 \mathrm{~cm}$ between 2000 and 2100 (Sweet et al. (2017). The screened Kopp et al. (2017) projections modify the Kopp et al. (2014) sea-level rise projection framework by substituting DeConto and Pollard's (2016) Antarctic ice-sheet projections which includes the aforementioned Antarctic Ice Sheet instabilities, while keeping other sea level components (Kopp et al., 2014) unchanged.

Preliminary ARIM scenario results for the 2020 s and 2050s remains within the pre-existing NPCC (2015) $10^{\text {th }}-90^{\text {th }}$ percentile range, because relative sea level trends within this range would not differ much from other sea level rise projections over the next few decades. The more extreme late- $21^{\text {st }}$ century ARIM outcome (designed to be consistent with a $250 \mathrm{~cm}$ global mean sea level rise, based on Sweet et al., 2017), implies a significant destabilization of marinebased portions of the Antarctic Ice Sheet. Physical modeling suggests that this would occur only after the second half of this century (DeConto and Pollard, 2016; Kopp et al., 2017; Le Bars et al., 2017; Wong et al., 2017).

Almost all scenarios suggest that sea level will continue to rise for centuries, even after greenhouse gas emissions have been curtailed. .Although the likelihood of occurrence of the ARIM scenario by 2100 is very small, it provides insights into larger possible sea level rises beyond 2100 .

To summarize, the sea level rise scenarios presented in NPCC (2015) are currently used in New York City resiliency planning. Because of the preliminary nature of the ARIM scenario (based in part on a new and controversial model), a unique, quantitative probability assignment is not yet possible. Nevertheless, stakeholders can obtain a sense of the potential range of outcomes for the 2080's and 2100 by keeping both ARIM and NPCC (2015) projections in mind.

One important consequence of an upperend sea level rise scenario, such as ARIM, is not only an increased frequency of coastal flooding, but also the progressive expansion of the floodplain over time with sea level rise (Section 4). Another possible consequence could be permanent inundation of low-lying neighborhoods by the end of the century that had previously experienced frequent tidal flooding (discussed further in Section 4).

Expansion of 100-Year Flood Zones with Sea Level Rise

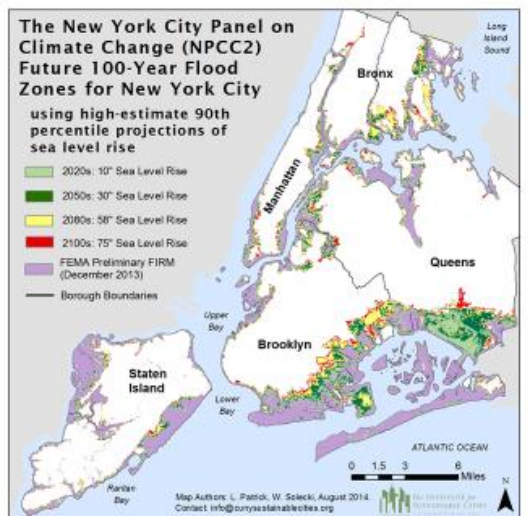


Figure 4. Future expansion of the 100-year flood zones in the 2020s, 2050s, 2080s, and 2100 under the $90^{\text {th }}$ percentile sea level scenario (NPCC, 2015).

\section{Sea Level Rise and Coastal Flooding}

\subsection{Future Coastal Storm Flood Risks}

The NPCC (2015) coastal flood assessment used simple superposition of the $90^{\text {th }}$ percentile sea level rise projection on the 2013 FEMA 100-yr flood maps as a baseline for various flood return periods and areal flood zones at future dates, keeping storm climatology changes fixed (Fig. 4). The same methodology (Orton et al. 2015a) is used in ongoing research, with the addition of the preliminary ARIM scenario results. Coastal flooding, in this context, is the resulting flood due to the combined effect of storm surge and the astronomical tide, also known as the "storm tide". (The 100-year flood is one that has a likelihood of occurring once per century, or $1 \% / \mathrm{yr}$, on average). Preliminary results show that an important consequence of an upper-end sea level rise scenario, such as ARIM, will not only be increased frequency of coastal flooding, but also the progressive expansion of the floodplain over time with sea level rise, beyond the current and NPCC (2015) 100-yr flood zones.

\subsection{Future Tidal Flooding}

One of the earliest manifestations of sea level rise is the increasing incidence of "nuisance flooding", or less extreme tidally related coastal flooding. Nuisance flooding has increased substantially in the United States between 1950 and 2013 (Sweet \& Marra, 2014; Sweet et al., 2014). Such increasing incidence of coastal flooding could potentially damage low-lying infrastructure and private homes, which in addition would be exposed to more frequent street, driveway, and basement flooding in the absence of adaptive measures. Several low-lying New York neighborhoods surrounding Jamaica Bay and Rockaway Peninsula already experience frequent "nuisance flooding." Other scattered locations around the city could face monthly high water by the 2080s and 2100 , under both the NPCC (2015) and ARIM SLR scenarios. In addition to an escalating frequency of tidal flooding, low-lying neighborhoods face an increased risk of permanent inundation by the end of the century, particularly in upper-end sea level rise scenarios. For example, many neighborhoods previously exposed to monthly tidal flooding by the 2050s and 2080s around Jamaica Bay and Coney Island under the $90^{\text {th }}$ percentile NPCC (2015) sea level rise projection might become submerged by 2100 under the ARIM sea level rise scenario, without additional coastal protection measures. Other parts of the city shoreline could face a similar situation. Many of these same neighborhoods were flooded during Hurricane Sandy.

\section{Sea Level Rise and New York City Coastal Resiliency}

New York City embarked on a major effort to enhance resiliency to future coastal flooding risks following Hurricane Sandy (SIRR 2013; NYC 2014a, b). Building codes have been strengthened: FEMA's National Flood Insurance Program (NFIP), which covers flood insurance for property owners residing within the FEMAdefined 100-year flood zone, has tightened regulations of minimum elevation of first floors in buildings within the most vulnerable subzones of the 100-year floodplain, and specified acceptable usages of such spaces. Other structural floodresiliency enhancements incorporate building flood-proofing (New York City, 2014a). Additional risk reduction strategies include temporary or permanent barrier site protection, utilization of flood-resistant materials in construction or retrofitting of buildings, and raising mechanical and electrical systems from basements. Further protections for critical infrastructure involve lifting air vent gratings over subways to prevent entry of water, elevating track switches and electrical equipment, increasing pumping capacity in underground rail and tunnel systems, and constructing new electric power substations beyond the flood zone. Other coastal defense measures include raising bulkheads, seawalls, and building neighborhood-scale levees and storm surge barriers.

In addition to these "hard", or structural improvements, the city also pursues "soft" pathways, such as recreation of native wetlands and construction of Living Shorelines with a mix of plants, soils, and rocks to dampen wave action and stabilize the shoreline (Figs. 5 and 6, NYC 2014b). In cooperation with the city, the United States Army Corps of Engineers undertakes periodic beach re-nourishment programs and dune restoration. The Brooklyn Bridge Park, located along a former industrial and shipping 
waterfront on the East River, is a model example of a Living Shorelines approach to coastal defense (Fig. 5). The shoreline along the park consists of a mix of bulkheads, riprap, newlyplanted salt marsh wetlands, salt-tolerant vegetation, and piers utilized for multi-purpose recreational activities.

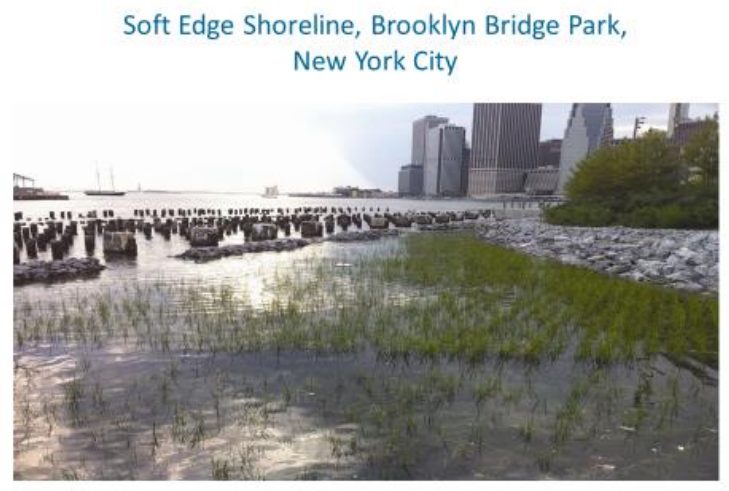

Source: Department of City Planning, City of New York City, 2011.

Figure 5. Brooklyn Bridge Park-an example of a Living Shoreline.

Coastal wetlands in Jamaica Bay provide wildlife habitat, recreation opportunities, water pollution filtration, and also help lessen flooding by damping wave action (Orton et al. 2015b). These salt marshes had greatly deteriorated during the 20th century due in part to historic sea level rise, past anthropogenic interventions, such as extensive dredging; landfill operations; bulkhead-hardened shorelines; curtailed sediment supply; and excess nitrogen loading from nearby wastewater treatment plants (Hartig et al. 2002; Boger et al. 2013, 2016). Ongoing wetlands restoration projects in Jamaica Bay aim to preserve habitat and attenuate storm-driven waves, in partnership with the New York City Department of Environmental Protection, NYC Department of Parks, New York State, and U.S. Army Corps of Engineers. Restoration efforts include replanting of marsh grass, restoring ribbed mussel habitat, and installing pilot wave attenuators to reduce shoreline loss and increase sediment accretion (Fig. 6).
Salt Marsh Restoration, Jamaica Bay

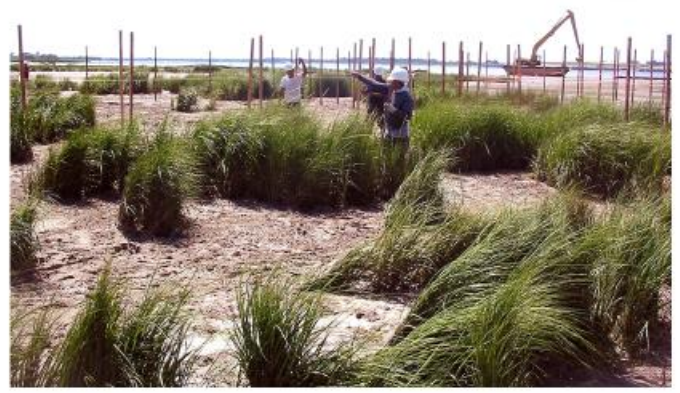

Figure 6. Replanting of salt marsh grass, Jamaica Bay, New York.

Much of New York City's resiliency actions described above address current or nearterm climate risks. However, as the previous sections imply, even if the ARIM scenario does not occur in 2100, much higher sea levels than previously anticipated, although a very low probability risk, are not out of the question later on.

Atmospheric $\mathrm{CO}_{2}$ has a long lifespan. Even upon total cessation of further anthropogenic $\mathrm{CO}_{2}$ emissions by mid-century, $\mathrm{CO}_{2}$ and atmospheric temperatures would gradually begin to diminish over several decades. However, most of the $\mathrm{CO}_{2}$ would still remain in the atmosphere and take centuries to millennia.to slowly dissipate. This long drawn-out diminution commits us to higher temperatures and ocean levels. We can therefore expect continued sea level rise well beyond 2100 , because of this and slow heat penetration into the deep ocean (Clark et al., 2016; Mengel et al., 2016; Golledge et al., 2015). Losses of ice on Greenland and Antarctica would continue during this extended period of sustained warmth, and could become quite substantial, leading, at worst, to significant deglaciation of the Greenland Ice Sheet $\$$ within 2,500-6,000 years at high emissions scenarios (Clark et al., 2016). Potential contributions from the West Antarctic Ice Sheet could add up to even greater losses. This raises the possibility of much higher sea levels than even that projected here for ARIM in future centuries.

In light of these considerations, will the current or planned near-term coastal resiliency

\footnotetext{
$\S$ The Greenland Ice Sheet holds the equivalent of $\sim 7$ meters of global-mean sea-level rise.
} 
measures underway in New York City suffice? The implications of substantial potential future economic and societal dislocations due to low probability, yet high consequence events affecting major urban centers such as New York City, underscore the importance of investigating upper-end sea level scenarios for long-term coastal risk management.

Obvious first coastal resiliency steps are to elevate levees, dikes, and study other options such as tidal barriers. Hill et al. (2008) proposed a set of three storm surge barriers at narrow points to protect the financial district of lower Manhattan, adjacent areas of Brooklyn, Queens, and the Bronx. The barriers would also shield Hoboken, Jersey City, and Newark, including Newark International Airport. However, large portions of Staten Island, Brooklyn, and Queens, including JFK International Airport, as well as nearby communities on the Atlantic coast of Long Island and Long Island Sound would remain exposed. Such an undertaking would also require thorough engineering and environmental impact studies as well as economic considerations. Alternatively, long-term coastal resiliency planning should include land-use zoning designed to minimize or avoid high-density development in flood-prone areas. As a last resort, planning for managed relocation of the most vulnerable areas may become necessary in the future.

\section{SUMMARY AND CONCLUSIONS}

Sea level rise for New York City and environs is projected to exceed the global average due to enhanced thermal expansion, ocean circulation changes, ice losses from glaciers and ice sheets and their associated "fingerprints", as well as continuing glacial isostatic adjustments. Sea level rise is expected to accelerate as the century progresses and could reach almost $1.5 \mathrm{~m}$ by the 2080s and up to $1.9 \mathrm{~m}$ by 2100 in the $90^{\text {th }}$ percentile estimate (NPCC, 2015). Recent escalating ice mass losses in Greenland and Antarctica, progress in modeling of ice sheet-ocean-atmosphere interactions, as well as potential West Antarctic marine ice shelf instability raise the prospects of much higher sea levels than previously foreseen. Preliminary results under the new upper-end ARIM scenario suggest a potential New York City sea level rise of over 2 meters by 2100, although deep uncertainties surround this very high estimate, which would occur only under highemissions futures.
The upper-end ARIM scenario, which incorporates potential ice sheet instabilities modeled by DeConto and Pollard (2016), considers the possibility that quite different mechanisms of Antarctic lce Sheet mass loss will dominate in the second half of this century than those prevailing in the first half, which differ little from previous results. Because of the non-linear nature of these ice sheet instabilities, moderate sea level changes in the next few decades do not rule out more extreme outcomes later on.

Sea level rise alone (assuming unchanged storm climatology) stands to increase the frequency and intensity of coastal flooding. Areas flooded by monthly high tides or episodically flooded by severe storms would expand inland over time as sea level continues to rise. Preliminary findings suggest that under the upper-end ARIM scenario, some of the lowestlying neighborhoods could become permanently submerged by 2100 . Substantial segments of the region's coastal population, infrastructure, and other built and natural assets in low-lying areas would thus encounter mounting hazards.

The implications of substantial economic and societal consequences to major coastal urban centers, such as New York City (e.g., Wahl et al., 2017, Hauer et al., 2016), underscore the need to incorporate such high impact, low probability upper-end scenarios into long-term coastal risk management. The latest trends in ice sheet behavior should continue to be monitored and sea level rise projections should be periodically updated by groups such as the NPCC. Future sea level rise projections beyond 2100 should be explored, given the longevity of atmospheric $\mathrm{CO}_{2}$. Long-term coastal resiliency planning should include land use zoning to discourage high density development in frequently-flooded areas. In addition to raising levees and dikes, and strengthening coastal defenses, new options such as tidal barriers may need to be considered. As a last resort, managed relocation of the most vulnerable areas may need to be implemented.

\section{REFERENCES}

Bamber, J.L., Riva, R.E.M., Vermeersen, B.L.A., and LeBrocq, A.M., 2009: Assessment of the potential sea-level rise from a collapse of the West Antarctic Ice Sheet. Science, 324, 901-903.

Boger R., Essrog, J., Christiano, M., 2013, 2016: Shoreline changes in Jamaica Bay, 
Gateway National Recreation Area, 1924-2006: implications for shoreline restoration, Integrating research and research and resource management in the national parks, PARK Science, 20(3). http://www.nature.nps.gov/parkscience/i ndex.cfm?ArticleID=648 (published online 5 Apr 2016).

Carson, M. et al., 2016: Coastal sea level changes, observed and projected during the $20^{\text {th }}$ and $21^{\text {st }}$ century. Clim. Change, 134, 269-281.

Chen X. et al., 2017: The increasing rate of global mean sea-level rise during 1993-2014. Nat. Clim. Change, 7, 92-497.

Church et al., 2013, in Climate Change 2013: The Physical Science Basis. Contribution of Working Group I to the Fifth Assessment Report of the Intergovernmental Panel on Climate Change. Stocker, T., Dahe, Q., Plattner, G.-K.,Tignor, M.M.B., Allen, S.K., Boschung, J., Nauels, A., Xia, Y., Bex, V., and Midgley, P.M., eds. Cambridge University Press: Cambridge, UK and New York, NY, USA, 1535pp.

Clark, P.U. and 21 others, 2016. Consequences of twenty-first century policy for multimillennial climate and sea level change. Nature Clim. Change, 6, 360-369.

Davies, Bethan, 2014: Is the West Antarctic Ice Sheet collapsing? http://www.antarcticglaciers.org/2014/05 /west-antarctic-ice-sheet-collapsing/ (posted 5/13/2014).

DeConto, R.M. and Pollard, D., 2016: Contribution of Antarctica to past and future sea-level rise. Nature, 531, 91597.

Dieng, H.B., Cazenave, A., Meyssignac, B., and Ablain, M., 2017: New estimate of the current rate of sea level rise from a sea level budget approach. Geophys. Res. Lett., 44, doi:10.1002/2017GL073308.

Gehrels, W.R. and Woodworth, P.L., 2013: When did modern rates of sea-level start? Glob. and Planet. Change, 100, 263-277.

Golledge, N.R., Kowalewski, D.E., Naish, T.R., Levy, R.H., Fogwill, C.J., and Gasson, E.G.W., 2015. The Multi-Millennial Antarctic Commitment to Future SeaLevel Rise. Nature 526, 421-425.

Gornitz, V., 2018. Vanishing Ice: Glaciers, Ice Sheets, and Rising Oceans. Columbia University Press, (in press).
Gornitz, V., Oppenheimer, M., Kopp, R., Orton, P., Buchanan, M., Lin, N., Horton, R., and Bader, D., 2018: Chapter 4. Sea level rise. In: New York City Panel on Climate Change 2018, Climate Science Foundations for Transformational Pathways. Rosenzweig C, Solecki W (eds) Ann. New York Acad. Sci., (in press).

Hartig, E.K., Gornitz, V., Kolker, A., Mushacke, F., Fallon, D., 2002: Anthropogenic and climate change impacts on salt marsh morphology in Jamaica Bay, New York City. Wetlands, 22, 71-89.

Hauer, M.E., Evans, J.M., and Mishra, D.R., 2016. Millions projected to be at risk from sea-level rise in the continental United States. Nature Clim. Change 6, 691-695.

Hay, Carling C., E. Morrow, R.E. Kopp, and J.X.Mitrovica, 2015: Probabilistic reanalysis of twentieth-century sea-level rise. Nature 517, 481-484.

Hill, D. 2008: Must New York City have its own Katrina? Leadership and Management in Engineering, 8 (3),132-38.

Horton, R., Little, C., Gornitz, V., Bader, D., and Oppenheimer, M., 2015: Chapter 2. Sea level rise and coastal storms. In: New York City Panel on Climate Change 2015 Report: Building the Knowledge Base for Climate Resiliency, Rosenzweig C, Solecki W (eds). Ann. New York Acad. Sci., 1336, 36-55.

IMBIE Team, 2018: Mass balance of the Antarctic Ice Sheet from 1992 to 2017. Nature 558, 219222.

IPCC. 2013. Climate Change 2013: The Physical Science Basis. Contribution of Working Group I to the Fifth Assessment Report of the Intergovernmental Panel on Climate Change. Stocker, T., Dahe, Q., Plattner, G.-K.,Tignor, M.M.B., Allen, S.K., Boschung, J., Nauels, A., Xia, Y., Bex, V., and Midgley, P.M., eds. Cambridge: Cambridge University Press.

Jevrejeva, S., Moore, J.C., Grinsted, A. Matthews, A.P., and Spada, G., 2014: Trends and acceleration in global and regional sea levels in 1807. Glob. Planet. Change, 113, 11-22.

Jevrejeva, S., Matthews, A., and Slangen, A., 2017: The twentieth-century sea level budget: recent progress and challenges. Surv. Geophys., 38:295-307.

Joughin, I., Smith, B.E., and Medley, B., 2014: Marine Ice Sheet Collapse Potentially 
Underway for the Thwaites Glacier Basin, West Antarctica. Science Express, $\quad 10.1126 /$ science.1249055. http://www.sciencemag.org/content/earl $\mathrm{y} / \mathrm{recent}$

Kopp, R.E., et al. 2014: Probabilistic 21st and 22nd century sea level projections at a global network of tide gauge sites. Earth's Future 2, 383-406.

Kopp, R.E., Kemp. A.C. Bittermann, K. et al., 2016. Temperature-driven global sealevel variability in the common era. Proc. Natl.Acad.Sci.: http://www.pnas.org/cdi/doi/10.1073/pna S.1517056113

Kopp, R. E., DeConto, R. M., Bader, D. A., Hay, C. C., Horton, R. M., Kulp, S., Oppenheimer, M., Pollard, D., \& Strauss, B. H., 2017: Evolving Understanding of Antarctic Ice-Sheet Physics and Ambiguity in Probabilistic Sea-Level Projections, Earth's Future, 5, 12171233.

https://doi.org/10.1002/2017EF000663

Krasting, J.P., Dunne, J.P., Stouffer, R.J., and Hallberg, R.W., 2016: Enhanced Atlantic sea-level rise relative to the Pacific under high carbon emission rates. Nature Geosci., 9, 210-214.

Le Bars, D., Drijfhout, S., and de Vries, H., 2017: A high-end sea level rise probabilistic projection including rapid Antarctic ice sheet mass loss. Environ. Res. Lett., 12:044013.

Mengel, M., Levermann, A., Frieler, K., Robinson, A., Marzeion, B., and Winkelmann, R., 2016. Future Sea Level Rise Constrained by Observations and Long-term Commitment. Proceedings of the National Academy of Sciences, 113(10), 2597-2602.

Orton, P., Vinogradov, S., Georgas, N., Blumberg, A., Lin, N., Gornitz, V., Little, C., Jacob, K., Horton, R., 2015a: Chapter 4: Dynamic coastal flood modeling. In: New York City Panel on Climate Change 2015, Rosenzweig C, Solecki W (eds). Ann. N. Y. Acad. Sci., 1336(1), 56-66.

Orton, P.M., Talke, S.A., Jay, D.A., Yin, L., Blumberg, A.F., Georgas, N., Zhao, H., Roberts, H.J., MacManus, K., 2015b: Channel shallowing as mitigation of coastal flooding. J. Mar. Sci. Eng., 3(3), 654-673, doi:10.3390/jmse3030654

Orton, P. M., Hall, T. M., Talke, S. A., Blumberg, A. F., Georgas, N., \& Vinogradov, S.,
2016: A validated tropical-extratropical flood hazard assessment for New York Harbor. J. Geophys. Res., Oceans, 121(12), 8904-8929.

New York City, 2014a: NYC's Risk Landscape: A Guide to Hazard Mitigation Flooding, Chapter 4.3.

http://www1.nyc.gov/assets/em/downloads/pdf/h azard mitigation/nycs risk landscape a

guide_to_hazard_mitigation_final_highres.pdf.

Accessed 7 Mar 2016

New York City, 2014b: NYC's risk landscape: a guide to hazard mitigation. Coastal erosion, $\quad$ Chapter 4.2 . http://www1.nyc.gov/assets/em/downloa ds/pdf/hazard_mitigation/nycs_risk_land scape_chapter_4.2_coastalerosion.pdf. Accessed 29 Feb 2016

Nerem, R.S., Beckley, B., Fasullo, J., Hamlington, B., Masters, D., and Mitchum, G., 2018: Climate change driven accelerated sea level rise detected In the altimeter era, Proc. Natl. Acad.

Sci. doi:10.1073/pnas, 1717312115

NPCC, 2015: New York City Panel on Climate Change 2015. Building the knowledge base for climate resiliency. Rosenzweig C, Solecki W (eds) Ann. New York Acad. Sci.,1336, $150 \mathrm{pp}$

NPCC, 2018: New York City Panel on Climate Change 2018. Climate Science Foundations for Transformational Pathways. Rosenzweig C, Solecki W (eds) Ann. New York Acad. Sci., (in press).

Rignot, E., Mouginot, J., Morlighem, M., Seroussi, H., and Scheuchl, B., 2014: Widespread, Rapid Grounding Line Retreat of Pine Island, Thwaites, Smith, and Kohler Glaciers, West Antarctica, from 1992 to 2011. Geophys. Res. Lett. 41, $3502-$ 3509, doi:10.1002/2014GL060140.

SIRR (2013) A stronger, more resilient New York, PlaNYC, The City of New York, Mayor Michael R. Bloomberg. http://www.nyc.gov/html/sirr/html/report/r eport.shtml/. Accessed 19 May 2016

Slangen, A.B.A., et al., 2016: Anthropogenic forcing dominates global mean sea-level rise since 1970. Nat. Clim. Change, 6,701-706

Slangen, A.B.A., et al., 2017: A review of recent updates of sea-level projections at global and regional scales. Surv. Geophys., 38, 385-406. 
Sweet, W.V. and Mara, J.J., 2015: 2014 State of Nuisance Tidal Flooding. http://www.noaanews.noaa.gov/stories2 015/2014/State of Nuisance Tidal Flo oding.pdf (accessed 4/26/17).

Sweet, W, Park, J, Marra ,J., Zervas, C., Gill, S.: 2014: Sea level rise and nuisance flood frequency changes around the United States, NOAA Tech. Rep.NOS CO-OPS 073.

Sweet, W.V., Kopp, R.E., Weaver, C.P. et al., 2017: Global and Regional Sea Level Rise Scenarios for the United States. NOAA Tech. Rep.NOS CO-OPS 083.

Talke, S.A., Orton, P., and Jay, D.A., 2014: Increasing storm tides in New York Harbor, 1844-2013. Geophys. Res.Lett.41, doi:10.1002/2014GL059574.

Wahl, T., Haigh, I.D., Nicholls, R.J., Arns, A., Dangendorf, S., Hinkel, J., and Slangen, A.B.A.., 2017. Understanding extreme sea levels for broad-scale coastal impact and adaptation analysis. Nature Communications 8,16075, doi:10.1038/ncomms 16075 .

Yin, J. and Goddard, P.B. 2013. Oceanic control of sea level rise patterns along the East Coast of the United States. Geophys. Res. Lett, 40, 514-5520, doi:10.1002/2013GL057992.

Yin, J., Schlesinger, M.E., and Stouffer, R.J. 2009: Model projections of rapid sealevel rise on the northeast coast of the United States. Nat. Geosc., doi:10:10.1038/NGEO462.

Yin, Y., Griffies, S.M., and Stouffer, R.S., 2010: Spatial variability of sea level rise in twenty-first century projections. J. Clim., 23, 4585-4607. 